\title{
Letter
}

\section{AIT test has no problem in the detection of anti-ribosomal $\mathbf{P}$}

\section{La-He Jearn and Think-You Kim}

\author{
Department of Early Arthritis/Laboratory Medicine, The Hospital for Rheumatic Diseases, Hanyang University Medical Center, 133-792 Seoul, Republic \\ of Korea
}

Corresponding author: Think-You Kim, tykim@hanyang.ac.kr

Published: 15 June 2009

This article is online at http://arthritis-research.com/content/11/3/407

Arthritis Research \& Therapy 2009, 11:407 (doi:10.1186/ar2705)

c) 2009 BioMed Central Ltd

See related research by Mahler et al., http://arthritis-research.com/content/10/6/R131

Mahler and colleagues posed a question on the reliability of the indirect immunofluorescence method using the HEp-2 cell line in their recent Arthritis Research and Therapy article [1]. Products from three different companies showed different staining patterns on the same anti-ribosomal $P$ (anti$\mathrm{Rib}-\mathrm{P}$ ) in the pictures they revealed. In addition to the antiRib-P that Mahler and colleagues mentioned, limitations of the HEp-2 cell line in the detection of autoantibodies such as anti-Ro have long been pointed out. The HEp-2000 cell line, which was developed to overcome such limitations, did not show any superior performance in the detection of anti-Rib-P since it was a form of HEp-2 cell that was transfected with cDNA encoding human Ro60. A human macrophage cell line called the IT-1 cell line was first introduced at the American College of Rheumatology meeting held in Minneapolis in 1994 [2], the same time as HEp-2000 was presented. IT-1 had been commercialized and passed inspection by the Korea Food and Drug Administration in South Korea. Currently, IT-1 is being used under the name of the autoimmune target (AIT) test and it participates in the quality control program run by the Korean Society of Laboratory
Medicine [3]. In 1999 and 2007, reports of antinuclear antibody test using the IT-1 cell line on 208 and 588 systemic lupus erythematosus (SLE) patients, respectively, showed a $100 \%$ positive rate that proved an exceptional improvement in the test performance [4,5]. Furthermore, the AIT test can indirectly help in the diagnosis of SLE using the microtubule organizing center pattern (MTOC) that can only be observed in the IT-1 cell line [4].

We investigated patients who were tested for anti-Rib-P using a double immunodiffusion method from April 1995 to March 2009. Anti-Rib-P was detected in 102 patients. AIT tests showed all positive results in anti-Rib-P-positive patients, and all patients showed a diffuse cytoplasmic pattern with no exception (Table 1). Although there were some differences according to other accompanying fluorescent patterns, most of the patients (100 patients, $98 \%$ ) showed a high titer of greater than 1:640 (Table 1).

Opinions about including anti-Rib-P in the diagnostic criteria of SLE have been recently suggested, like Mahler and

Table 1

Immunofluorescence patterns and titers of the autoimmune target test in anti-ribosomal P-positive patients

\begin{tabular}{|c|c|c|c|c|c|}
\hline \multirow[b]{2}{*}{ Immunofluorescence patterns } & \multicolumn{4}{|c|}{ Titer of diffuse cytoplasmic pattern } & \multirow[b]{2}{*}{ Total patients } \\
\hline & $1: 320$ & $1: 640$ & $1: 1,280$ & $\geq 1: 2,560$ & \\
\hline Diffuse cytoplasmic only & 0 & 1 & 7 & 15 & 23 \\
\hline Diffuse cytoplasmic + nucleolar & 0 & 4 & 4 & 20 & 28 \\
\hline Diffuse cytoplasmic + nucleolar + others & 0 & 3 & 2 & 3 & 8 \\
\hline Diffuse cytoplasmic + others & 2 & 8 & 11 & 22 & 43 \\
\hline Total & 2 & 16 & 24 & 60 & 102 \\
\hline
\end{tabular}

AIT = autoimmune target; anti-Rib-P $=$ anti-ribosomal $P ; S L E=$ systemic lupus erythematosus. 
colleagues' article. We agree that anti-Rib-P, just like anti-Sm or anti-nDNA, could be considered an effective marker antibody in the diagnosis of SLE. We would like to insist, however, that the improvement of the antinuclear antibody test substrate, which is the important diagnostic tool for SLE, is the foremost agenda to be dealt with.

\section{Competing interests}

T-YK holds patents relating to the IT-1 cell line.

\section{References}

1. Mahler M, Ngo JT, Schulte-Pelkum J, Luettich T, Fritzler MJ: Limited reliability of the indirect immunofluorescence technique for the detection of anti-Rib-P antibodies. Arthritis Res Ther 2008, 10:R131.

2. Kim TY, Chang SY, Kim SY: A new substrate (IT-1) for the antinuclear antibody (ANA) test [abstract]. Arthritis Rheum 1994, 37(Suppl):S317.

3. Kim TY: An external quality assurance program for autoimmune tests. Korean J Lab Med 2006, 26(Suppl):S350-S352.

4. Kim TY, Oh J: Anti-MTOC is not found in SLE [abstract]. Korean $J$ Lab Med 1999, 19(Suppl):S366.

5. Sung YK, Hur NW, Sinskey JL, Park D, Bae SC: Assessment of damage in Korean patients with systemic lupus erythematosus. J Rheumatol 2007, 34:987-991. 